\title{
EDUCATING FOR INTERDISCIPLINARY COMPETENCES: A VIVES-FRAMEWORK
}

\author{
Elien Sabbe, David Wemel, VIVES University of Applied Sciences, Belgium
}

\section{Situating interdisciplinarity in VIVES}

Nowadays professionals function in a society that is changing faster and faster. They face complex questions and challenges for which a mere (mono)disciplinary approach is no longer sufficient (Holley, 2017; Spelt, Biemans, Tobi, Luning, \& Mulder, 2009). For VIVES, it is therefore both a necessity and an asset that students are equipped with solid domain specific knowledge and skills as well as with broader competences, the so-called competences for the $21^{\text {st }}$ century. One of those broader competences is the competence for interdisciplinary cooperation.

VIVES is investing a lot in interdisciplinarity. In our VIVES-research (VIVES, 2016), we explicitly choose for interdisciplinary centres of expertise. Also in the lab-approach of education, our make-lab, a care-lab and a simulation-lab are seen as real hubs for interdisciplinarity. In our VIVES-vision on education, we aim to prepare student for the jobs and the society of tomorrow (VIVES, 2014). That is why we so strongly stress the importance of interdisciplinary competences in our policy documents: the VIVES vision on education, the VIVES-competences for the $21^{\text {st }}$ century and the VIVES-framework for quality assurance of our study programmes (VIVES, 2018). Our educational policy plan for the period 20172022 points out the necessity to create enough space for interdisciplinary cooperation in the curricula and demands that every study programme is cooperating interdisciplinary with at least one other study programme in at least one course (VIVES, 2017).

Students don't learn to cooperate interdisciplinary on their own (Holley, 2017; Spelt, Biemans, Tobi, Luning, \& Mulder, 2009). It is therefore crucial for study programmes to choose explicitly for well targeted learning activities and assessments that really contribute to the acquisition of interdisciplinary competences. Moreover, those activities are stronger if they are embedded in what we call "connected curricula" (VIVES, 2017). We shouldn't treat interdisciplinarity as something separate or besides the curriculum, but as fully integrated in the existing curricula. To support this vision and in order to get a clear view on the level of integration of interdisciplinarity in our curricula, VIVES has developed the framework we will describe below. 


\section{The framework}

\section{The 7 axes}

Designing curricula that stimulate interdisciplinary cooperation is a complex interaction between content, methods and organisation. In order to make this complex reality comprehensible, we have selected seven core-elements to build the framework. These 7 elements are based upon research results and practical experience in literature (Holley, 2017; Hogeschool UC Leuven-Limburg, 2017; Spelt, Biemans, Tobi, Luning, \& Mulder, 2009). and in practice. For each of the elements we have developed an axe on which the single course or the entire curriculum can be positioned.

1. Students: Which students encounter interdisciplinarity in their programme? (Individual students $\rightarrow$ All students)

2. Society and professional field: How do students experience interdisciplinarity in their contacts with the professional field or broader society? (Exploration $\rightarrow$ Interdisciplinary cases by and for professional partners)

3. Level of interdisciplinarity: Multidisciplinarity $\rightarrow$ transdisciplinarity

4. Scope: Different study programmes in the same faculty (narrow scope) $\rightarrow$ Interdisciplinary cooperation between faculties (large scope)

5. Embeddedness: Impact of interdisciplinary cooperation on the educational activities. (interdisciplinary cooperation between teachers (to enrich their content) $\rightarrow$ interdisciplinarity as a learning outcome)

6. Alignment: Level of alignment between learning outcomes, learning activities and assessment (Biggs, 1996)

7. Coherence: The way in which activities aimed at interdisciplinarity are connected. (individual or isolated activities or courses $\rightarrow$ strong integration in the whole curriculum)

For each of the axes, a 3-level scale with a description for each level has been developed.

\section{Individual student}

- Whether or not students come into contact with interdisciplinarity depends on the student's choices for certain subjects.

\section{Sub-groups of students}

- Certain sub-groups of students (e.g. specific subjects or in certain group works) come into contact with interdisciplinarity.

\section{All students}

- Interdisciplinarity is an integral part of the curriculum of all students following the programme.

Axe 1: Students 


\section{Exploration of} interdisciplinarity in the professional field/society

- Students get to know the interdisciplinary character of the professional field/society through company visits, practical examples, cases,...

- Students do not actively work interdisciplinarily in and with the professional field/society.
Interdisciplinary cases

from the professional field/society

- Students actively work with interdisciplinary

cases/assessments/problem propositions from the field or society.

- Students must be able to connect core concepts from their own discipline with other relevant disciplines in a (simulated) educational situation.

- The guidance and evaluation in the elaboration of the cases by the students takes place within (simulationeducation in) VIVES.
Interdisciplinary cases

with and for the

professional field

- Students actively work with interdisciplinary

cases/assessments/problem propositions with and for the field of work or society.

- Students connect core concepts from their own discipline with other relevant disciplines in order to contribute to a solution/execution of the case with and for the field of work or society.

- The guidance and evaluation in the elaboration of the cases takes place in collaboration with the interdisciplinary field of work or society.

Axe 2: Society and professional field

\section{Multidisciplinary \\ - Different disciplines each contribute with their own expertise. \\ - Expertise remains side by side. \\ - There is no knowledge transfer or integration between disciplines.}

\section{Interdisciplinary}

- Interaction between experts and integration of expertise from different disciplines.

- Boundaries between the different disciplines remain.

- Common goals and products (which could not arise from the individual discisplines).

Axe3: Level of interdisciplinarity

\section{Transdisciplinary}

- Co-creation by experts from different disciplines and nonexperts (experts by experience).

- Boundaries between disciplines disappear, people (partially) move into each other's field of work or environment.

-A new set of shared knowledge or solutions is created for a disciplinetranscending authentic problem. 


\section{Narrow}

\section{interdisciplinarity}

- Cooperation between different specialisations within the same study programme.

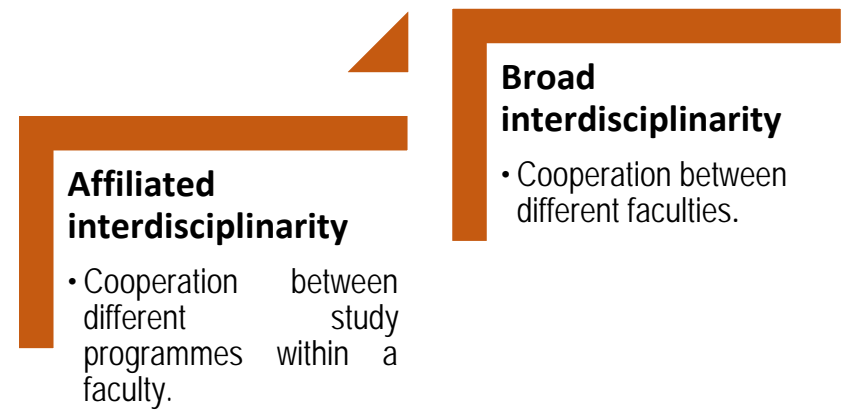

Axe 4: Scope

\section{Interdisciplinary \\ cooperation between teachers or programmes}

- Teachers or researchers work together interdiscplinarily, but the education is not interdisciplinary. There is therefore no or only a limited impact on education, learning and testing activities due to the interdisciplinarity in the teaching team.

\section{Students come into contact with interdisciplinarity}

-Students come into contact with content from different disciplines or with teachers, guest speakers, professionals from the field from different disciplines, making them aware of interdisciplinarity, but there is no targeted focus on interdisciplinary learning to cooperate.
Education, learning activities and assessment aimed at competences for interdisciplinary cooperation

-Targeted and explicit teaching, learning activities and assessment are used to teach students to work together in an interdisciplinary way.

Axe 5: Embeddedness 


\section{Is implicitly addressed}

- The curriculum includes interdisciplinary initiatives, but these are not named as such or the intended competences for interdisciplinary cooperation are not explicitly formulated or communicated to the students.

\section{Explicit purpose of teaching and learning activities}

- The curriculum explicitly aims at competences for interdisciplinary cooperation and contains deliberately chosen teaching and learning activities.

- Students are explained why they have opted for certain teaching and learning activities based on competences for interdisciplinary cooperation and what the expectations are.

Axe 6: Alignment

\section{Systematically assessed}

- Throughout the programme, the competencies for interdisciplinary cooperation are assessed formatively or summatively (preferably at different moments in the programme).

- Students reflect and/or receive (preferably interim) feedback on the extent to which they have acquired competencies interdisciplinary cooperation.

\section{Several related initiatives \\ - In the curriculum there are some interdisciplinary initiatives which are to a limited extent interlinked or coordinated with other educational, learning activities and assessment.}

Axe 7: Coherence

\section{Integrated perspective}

-Interdisciplinary teaching, learning and assessment activities are integrated by the training team into the curriculum in a balanced, coherent and targeted way.

-Moreover, there is an accumulation in complexity, difficulty and degree of integration in the interdisciplinary teaching, learning activities and assessments throughout the different phases of the programme.

- The acquisition of competences for interdisciplinary cooperation or underlying competences is preferably linked to the acquisition of other related competences (e.g. cooperation and communication, research competences, criticalreflexive competences, etc.). learning objectives in the programme.

\section{Interdisciplinary profile}

(Teams of) teachers can now build an interdisciplinary profile of their course or their study programme. We bring together the seven axes in a spider diagram in order to visualise the level of interdisciplinarity for a course or a study programme. The diagram can be used in a static way, by using it to take a picture from the current level of interdisciplinarity (as is), or it 
can be used in a more dynamic way, by also visualising the desired level of interdisciplinarity (as should be) in the same diagram.

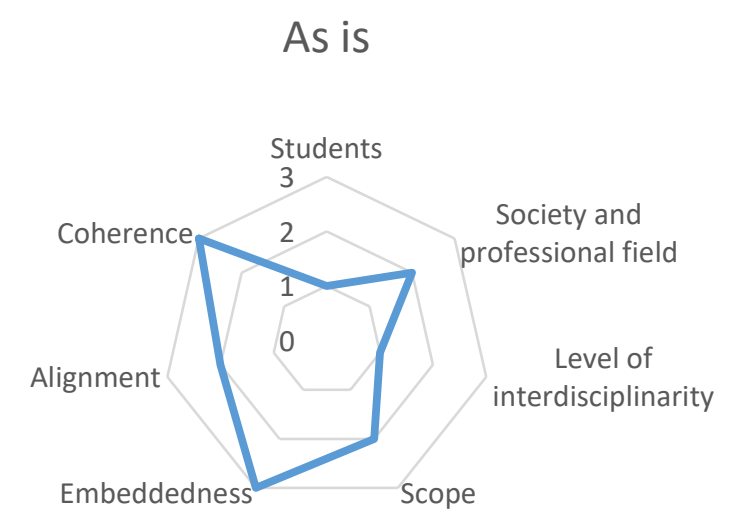

Figure 1. Static use of the spider diagram

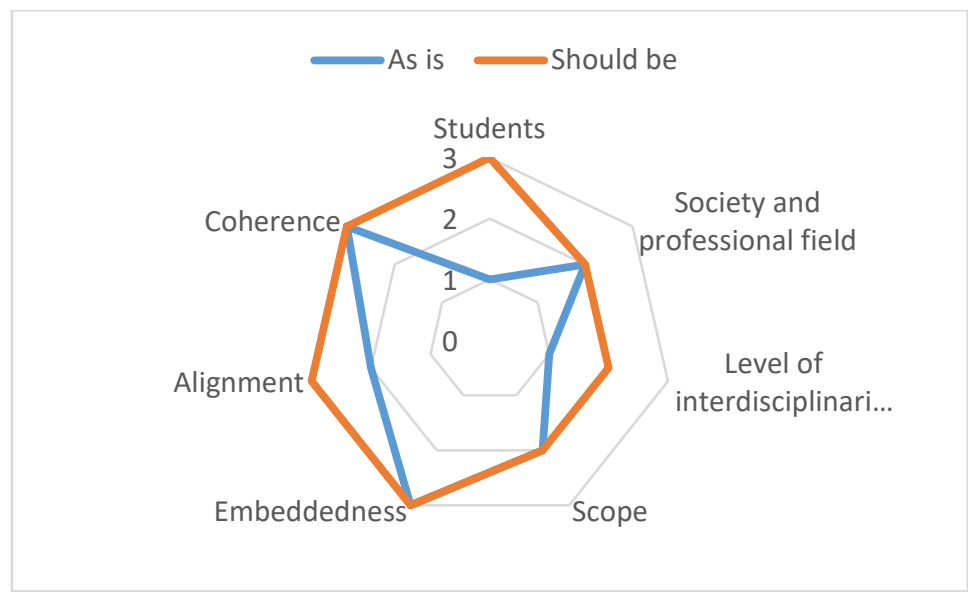

Figure 2. Dynamic use of the spider diagram

\section{Action plans}

A next step for teacher teams can then be to make up an action plan to make the shift from the situation "as is" towards the situation "as it should be".

\section{Discussion}

In VIVES, our educational policy plan for the period 2017-2022 points out the necessity to create enough space for interdisciplinary cooperation in the curricula and demands that every study programme is cooperating interdisciplinary with at least one other study programme in at least one course (VIVES, 2017). This framework offers a tool for teacher teams to "score" the level of interdisciplinarity in their study programme. For some of the axes we pointed out a minimum score to make clear what is the absolute minimum level of interdisciplinarity we expect from our different study programmes. In other words, this is where the "as is" line needs to be for every single study programme by the end of 2022. Off course, we stimulate our teachers to be more ambitious in their positioning of the "should be" line, but we also 
recognise that the desired level of interdisciplinarity can be different for every study programme due to, among other things, context reasons.

In our quest for more education for interdisciplinary competences, we often encounter practical obstacles. When two or more study programmes need to collaborate, time and space issues appear. In the case of VIVES for example, our campuses are located in five different cities across the province. Therefore, interdisciplinary courses often require mobility between two or more campuses. This is considered time consuming, inefficient and less sustainable. Moreover, the issues of time and space are even more present in a context of distance education.

An emerging question is how to develop distance education curricula with components of interdisciplinarity and how educational technology can help us to overcome issues of time and space in a context of interdisciplinary education both for distance education as for regular study programmes.

\section{References}

Biggs, J. (1996). Enhancing teaching through constructive alignment. Higher Education., 32(3), 347.

Holley, K. (2017). Interdisciplinary Curriculum and Learning in Higher Education. Oxford Research Encyclopedia, Education.

Hogeschool UC Leuven-Limburg (2017). Transdisciplinair onderwijs. Inspiratiegids. Onderwijsontwikkelingsfonds (OOF) Horizon.

Lattuca, L. (2001). Creating interdisciplinarity: interdisciplinary research and teaching among college and university faculty. Nashville: Vanderbilt University Press.

Spelt, E. J. H., Biemans, H. J. A., Tobi, H., Luning, P. A., \& Mulder, M. (2009). Teaching and Learning in Interdisciplinary Higher Education: a systematic review. Journal of Educational Psychology Review, 21(4), 365-378.

VIVES dienst onderwijsbeleid (2014). De missie, strategische krachtlijnen en onderwijsvisie van VIVES.DO@Vives nr. 1.

VIVES dienst onderwijsbeleid (2016). Competent voor de 21e eeuw. DO@Vives nr. 8.

VIVES dienst onderwijsbeleid (2017). Onderwijsbeleidsplan 2017-2022. DO@Vives, nr. 12.

VIVES dienst onderwijsbeleid (2018). Kwaliteitszorg van een opleiding. VIVESreferentiekader 2017-2022. DO@VIVES nr. 15.

VIVES dienst onderzoek en dienstverlening (2016). Onderzoeksbeleidsplan 2016-2020. Kortrijk: hogeschool VIVES. 